\title{
The next generation of physicians
}

\author{
Author: David Black ${ }^{A}$
}

Nothing can be more important to the three physicianly colleges than ensuring the supply and training of the next generation of physicians. It is as important now as it was when the London College was set up nearly 500 years ago in 1518 .

For the last 20 years the job of being a consultant has changed out of all recognition. Driven by evidence-based medicine, most physicians' roles have become increasingly specialised and with that, increasingly effective with better patient outcomes. Yet the demography of the population is becoming older, and hospitals are being faced with an apparent tidal wave of patients with multiple problems and comorbidities. The Future Hospital Commission explored this in great detail and set out a pathway to try and find a balance between the need for generalism and specialism in the skill set of both individual clinicians and organisations. ${ }^{1}$ Much of the same ground was covered by the Shape of Training report ${ }^{2}$ which challenges the medical profession to find an affordable way to ensure that all patients' needs (both specialist and generalist) are being met and that clinical training remains flexible enough to be able to cope with both rapid changes in medical provision for the next 50 years and the associated longer working lives.

These challenges to the work of physicians are reflected in how we train doctors today and how we will train them in the next 10-20 years.

In this journal there is an important article by Bill Burr, the recently demitted medical director of the Joint Royal Colleges of Physicians Training Board (JRCPTB), and Fiona Tasker, clinical fellow to the president of the Royal College of Physicians (RCP), which sets out some of the challenges that core medical trainees are facing as well as some of the ideas that have been put forward to improve their training. ${ }^{3}$

At first glance, the situation may seem rather negative and the frustrations of some core medical trainees, with the poor educational and training experiences that occur in some sites and with some supervisors, are clear. It also reflects the huge pressure and workload the service is expecting of these trainees, which means that important parts of their training, such as outpatients, are being neglected. However, this survey undertaken by the RCP and the JRCPTB is only one piece of evidence; the national General Medical Council Survey, which gets over $99 \%$ completion, while showing year-to-year variation, found that overall satisfaction with core medical

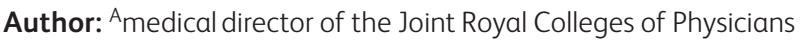
Training Board, London, UK training has increased year-on-year if we look at the UK as a whole. Comparing 18 local education and training boards (LETBs) and deaneries between 2012 and 2014, 14 of the 18 deaneries/LETBs demonstrate increased overall satisfaction by core medical trainees. ${ }^{4} \mathrm{~A}$ further piece of evidence is recruitment. After general practice, core medical training is the single largest specialty to be selected into from foundation. Core medical training is of course extremely good training for many different branches of medicine and importantly national recruitment of core medical trainees has achieved essentially $100 \%$ fill across the UK in the last two years. This has been at a time when there has been a small expansion in CMT numbers despite increasing national pressure to increase general practice training fill rates. To some extent both specialties are 'fishing in the same pool', but despite the challenges, the experiential learning and opportunities of core medical training continue to appear attractive for the next stage of career development for young doctors completing foundation training. Additional evidence for improvement in core medical training has been the data provided by $\mathrm{MRCP}(\mathrm{UK})$. This shows year-on-year overall increases in the number of doctors who have obtained Part I, Part II and PACES at each stages of core medical training (Dr Andrew Elder, personal communication). But work also demonstrates how much variation there remains around the country between deaneries/LETBS.

The paper by Burr and Tasker also sets out some ideas, good practice and proposals to improve and develop core medical training. An important next step that has been supported by heads of school, trainees and Health Education England has been the production of quality criteria for core medical training, which are being launched in early 2015. These set out some challenging criteria by which high quality programmes for core medical training can be judged. Some of these, for example that all core medical trainees must undertake 40 outpatient clinics over the two years, we would like to see incorporated into the curriculum, but that is difficult to do until it can be demonstrated that this is achievable rather than just an aspiration. It is hoped that by publishing comparative data for a national audit we can continually drive up standards (after all doctors seem naturally competitive), as well as giving trainees more information about where they should apply.

A major reform started in August 2014 has been the Specialty Trainee Assessment and Review (STAR) Programme, following a very large trial in three Deaneries between 2012 and 2013. ${ }^{5}$ This has completely overhauled the way workplace-based assessments are used and whether they are for learning or of learning. Importantly for educational supervisors, 
competencies are now sampled rather than tediously ticked off and this should give considerably more and productive time for feedback and discussion with educational supervisors.

A third strand has been to completely review where we are with simulation-based training. Around the UK there is a large amount of 'kit', but there is still a long way to go in developing faculty and being clear which part of the core medical training curriculum must be taught by simulation and which parts can be enhanced. However all foundation doctors now get access to simulation-based training each year so this must also become routine for improving core medical training. So overall, there are certainly grounds for optimism that we are making some progress towards improving core medical training, but the improvement is slow.

Core medical training is the underpinning of all physicianly specialties for progression to higher specialty training. The completion of core medical training, for which passing all parts of MRCP(UK) is a requirement, is set at a standard that those completing are able to become a medical 'registrar' and run the acute take. It is an important but also a challenging step. The core medical trainee survey described by Burr and Tasker $^{3}$ found support for the many anecdotal comments that the step up from CMT2 to ST3, where there is responsibility for the acute take, is seen by many trainees as quite daunting. The RCP has previously documented the high work load and expectations from day 1 of being a medical registrar. ${ }^{6} \mathrm{~A}$ particular cause of anxiety is the increasing difficulty in not just getting experience, but becoming highly expert, in undertaking procedures. While the core medical training curriculum reflects current practice, there is still misunderstanding on the part of employers about their responsibilities to support, and sometimes train, newly appointed registrars in all aspects of running the acute take in particular procedures out of hours. The Federation of the Royal Colleges of Physicians has previously issued advice and guidance on procedures and supporting new registrars, ${ }^{7}$ but anecdotally some trusts still seem to fail in what is a clear clinical governance issue.

A further problem is that there is still not adequate filling of ST3 opportunities in physicianly specialties. In 2014, as in the previous year, only around $75 \%$ of national training number (NTN) opportunities were filled in the first round in the 19 participating specialties in JRCPTB-run national recruitment. This will rise to nearer $85 \%$ after round 2 but still leaves gaps in a number of the acute specialties. This then feeds through to inadequately manned rotas and increased pressure on those delivering service.

JRCPTB and the Federation of the Medical Royal Colleges are determined to do everything possible to improve supporting the work and training of all medical registrars. Increasing core medical trainee numbers is important as more people will be in the pool for ST3 opportunities. Encouraging growth of specialties such as geriatric medicine is vital; indeed geriatric medicine has had 45 new NTNs over the last three years and the absolute number of people going into geriatric medicine has also increased year on year. Those with recently acquired skills in core training can expect to use them for some of the early years of specialty training; ${ }^{8}$ this is not just a service issue but allows many of the more generic physicianly competencies to be acquired alongside other aspects of higher specialty training. The fact is though that these are all 'sticking plaster' solutions. We need radical thinking about the early years of training and the debate around the Shape of Training has started that. JRCPTB will be pressing for longer generic training in internal medicine, longer placements at all stages of physicianly training (6 months not 4 months), much greater use of simulation and the possibility of a 'junior' registrar year before final selection into specialty training. Certainly we foresee most hospitals needing two Registrars on 24/7 in the very near future.

\section{Conclusion}

Core medical training is challenging but remains popular, with evidence of slow improvement. A real challenge remains delivery of enough highly skilled registrars and then consultants, to run the acute take safely while feeling supported as part of proper continuum of training.

\section{References}

1 Future Hospital Commission. Future hospital: caring for medical patients. A report from the Future Hospital Commission to the Royal College of Physicians. London: RCP, 2013. Available online at www.rcplondon.ac.uk/sites/default/files/future-hospital-commission-report.pdf [Accessed 16 September 2014].

2 The Shape of Training Review. Securing the future of excellent patient care the final report of the Shape of Training Review. Available online at www. shapeoftraining.co.uk/static/documents/content/Shape_of_training FINAL_Report.pdf_53977887.pdf [Accessed 16 September 2014].

3 Tasker F, Dacombe P, Goddard AF and Burr B. Improving core medical training - innovative and feasible ideas to better training. Clin Med 2014;14:612-7.

4 General Medical Council. National training survey 2014: Key findings. Available online at www.gmc-uk.org/NTS_2014_KFR_A4. pdf_56706809.pdf [Accessed 16 September 2014].

5 Joint Royal Colleges of Physicians Training Board. Recommendations for specialty trainee assessment and review: Incorporating lessons learnt from the workplace-based assessment pilot. JRCPTB, 2014. Available online at www.jrcptb.org.uk/assessment/Pages/Workplace-BasedAssessment.aspx [Accessed 16 September 2014].

6 Royal College of Physicians. The medical registrar: empowering the unsung heroes of patient care. London: RCP, 2013.

7 Federation of the Royal Colleges of Physicians of the United Kingdom. Governance Statement regarding patient safety issues in relation to practical procedures carried out by trainee doctors in physicianly specialties - updated statement May 2013. Available online at www.jrcptb.org.uk/trainingandcert/Documents/Procedures\%20 Statement\%20May\%202013.pdf [Accessed 16 September 2014].

8 Federation of the Royal Colleges of Physicians of the United Kingdom. Supporting the Acute Take: Advice for NHS Trusts and Local Health Boards. Available online at www.rcplondon.ac.uk/sites/ default/files/supporting_the_acute_take_-_final_statement.pdf [Accessed 16 September 2014].

Address for correspondence: Prof D Black, JRCPTB, 11 St Andrews Place, London, NW1 4LE, UK. Email: david.black@rcplondon.ac.uk 